Еволючія кондуктометричного підходу до встановлення поведінки іонів четвертинних амонієвих солей у розчинах / К. С. Ютілова, О. М. Швед // Вісник Донецького національного університету імені Василя Стуса. Серія хімічні науки. 2017. № 1. С. 4-13

УДК 543.555+544.353.3+543.632.562.4

\title{
ЕВОЛЮЦІЯ КОНДУКТОМЕТРИЧНОГО ПІДХОДУ ДО ВСТАНОВЛЕННЯ ПОВЕДІНКИ ІОНІВ ЧЕТВЕРТИННИХ АМОНІСВИХ СОЛЕЙ У РОЗЧИНАХ
}

\author{
К. С. Ютілова*, О. М. Швед \\ Донецький національний університет імені Василя Стуса, м. Вінниця, Україна
}

\begin{abstract}
Розглянуто метод кондуктометрії як спосіб визначення констант іонної рівноваги у розчинах електролітів. Описано моделі іонної асоціації і методи математичної обробки кондуктометричних даних - від класичних до сучасних. Адекватність моделей проілюстровано експериментальними прикладами. Проаналізовано залежності граничної молярної електропровідності від властивостей електроліту та розчинника. Показано, що у розчинах четвертинних амонієвих солей відбуваються процеси асоціації.

Ключові слова: електропровідність, кондуктометрія, четвертинні амонієві солі, іонні пари, константа асоціації.
\end{abstract}

\section{Вступ}

Реакційна здатність та каталітична активність четвертинних амонієвих солей (ЧАС) значною мірою залежить від характеру їх взаємодії з розчинником [1]. У середовищах з низькою електричною проникністю відбуваються процеси асоціації іонів, а саме утворення іонних пар та трійників (схеми 1 і 2, відповідно) [2, 3].

$$
\begin{gathered}
\mathrm{A}^{-}+\mathrm{B}^{+} \underset{K_{c}}{\stackrel{K_{a}}{\rightleftarrows}} \mathrm{A}^{-} \mathrm{B}^{+} \\
\mathrm{A}^{-} \mathrm{B}^{+}+\mathrm{A}^{-} \\
\mathrm{A}^{-} \mathrm{B}^{+}+\mathrm{B}^{+}
\end{gathered}
$$

Найбільш зручним і достатньо точним для дослідження іон-сольвентних та іон-іонних взаємодій у розчинах ЧАС $€$ кондуктометричний метод [4], за яким визначають величини електропровідності солей. 3 цих експериментальних даних розраховують величини констант дисоціації або асоціації іонів у розчинах, які дають змогу зробити висновок щодо стану сполуки у конкретному розчиннику.

Проблема визначення електропровідності електролітів у неводних середовищах полягає у тому, що ступінь дисоціації та коефі- цієнти активності іонів можуть значно відрізнятися від одиниці [5]. Константи дисоціації для слабких електролітів знаходять за формулою (3) [6]:

$$
K_{c}=\frac{c \lambda^{2}}{\lambda^{0}\left(\lambda^{0}-\lambda\right)},
$$

де $K_{c}$ - константа дисоціації слабкого електроліту, моль/л; $c$ - молярна концентрація, моль/л; $\lambda$ - молярна електропровідність, См·см²/моль; $\lambda^{0}-$ молярна електропровідність при граничному розведенні, См·см²/моль. Формула (3) є виразом закону розведення Оствальда через молярні електропровідності, якщо $\alpha=\lambda / \lambda^{0}$. Величина граничної електропровідності електроліту є сумою граничних електропровідностей катіона й аніона $\lambda_{\kappa}^{0}$ і $\lambda_{\mathrm{A}}^{0}$, відповідно формулі (4):

$$
\lambda^{0}=\lambda_{\mathrm{K}}^{0}+\lambda_{\mathrm{A}}^{0}
$$

Величини $\lambda_{\kappa}^{0}$ і $\lambda_{\mathrm{A}}^{0}$ визначено для обмеженої кількості речовин переважно у водному середовищі. Таким чином, знаходження констант дисоціації ЧАС в органічних середовищах, а також у бінарних та більш складних розчинниках, вимагає застосування іншої математичної моделі.

\footnotetext{
* E-mail: k.iutilova@donnu.edu.ua

(C) К. С. Ютілова, О. М. Швед, 2017
} 


\section{1. Визначення констант дисоціації методом Крауса-Брея}

Краус і Брей у своїй класичній праці [7] виклали екстраполяційний метод визначення константи дисоціації. Вираз для закону розведення Оствальда (3) автори методу привели до вигляду (5), тобто до лінійної залежності

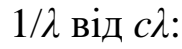

$$
\frac{1}{\lambda}=\frac{1}{\lambda^{0}}+\frac{c \lambda}{K_{c}\left(\lambda^{0}\right)^{2}}
$$

Побудова графіку у цих координатах дає значення кутового коефіцієнту $1 / K_{c}\left(\lambda^{0}\right)^{2}, 3$ якого визначають величину константи дисоціації $K_{c}$ (рис. 1).

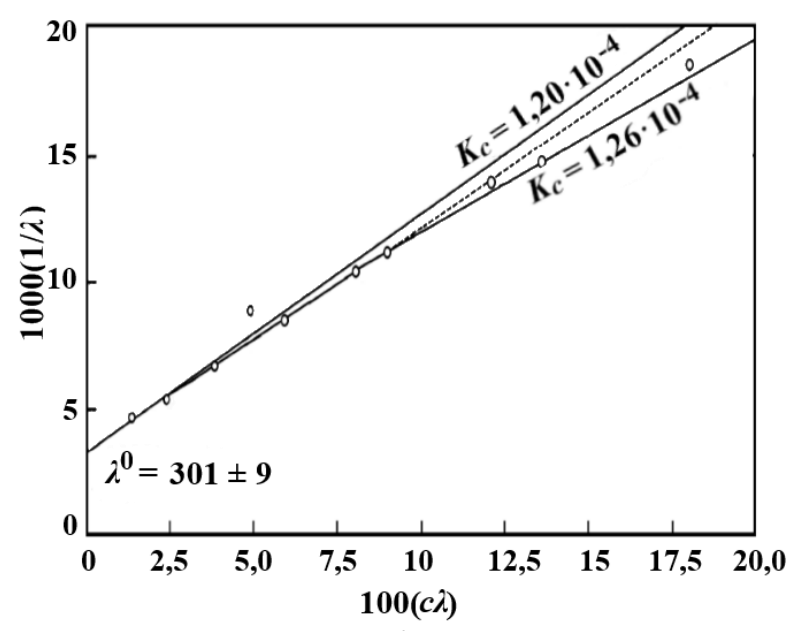

Рис. 1. Визначення $K_{c}$ і $\lambda^{0}$ для $\mathrm{KNH}_{2}$ у амоніаку за температури $33,5^{\circ} \mathrm{C}$ за методом Крауса і Брея [7]
Проте метод Крауса-Брея не відображає міжіонної взаємодії і не враховує можливості утворення іонних пар і триплетів, тому його використання обмежене. Він є достатньо достовірним для сильно розведених розчинів слабких електролітів, зокрема, лікарських препаратів, у тому числі ЧАС [6]. Цим методом досліджували поведінку тіамін гідрохлориду (вітамін $\mathrm{B}_{1}$ ) у водно-етанольних $(\mathrm{EtOH})$ сумішах [8] та піридиній дихромату у водно$\mathrm{N}, \mathrm{N}$-диметилформамідних сумішах (DMFA) [9] (табл. 1).

В обох розглянутих випадках спостерігається послідовне зниження електропровідності розчинів зі зменшенням діелектричної проникності шляхом додавання до водного середовища менш полярних розчинників. Таким чином, експериментальні дані узгоджуються із теоретичними уявленнями про асоціацію іонів ЧАС в органічних розчинниках.

\section{2. Рівняння Фуосса-Крауса}

Пізніше Фуосс і Краус [10] запропонували інший графічний метод визначення $K_{c}$, що враховує взаємне притягання іонів і його вплив на активності іонів та електропровідність [3]. Рівняння Фуосса-Крауса має вигляд (6):

$$
\frac{F(Z)}{\lambda}=\frac{1}{\lambda^{0}}+\frac{\lambda f_{ \pm}^{2} c}{K_{c}\left(\lambda^{0}\right)^{2} F(Z)},
$$

де $F(Z)=1-B \sqrt{c \alpha} / \lambda^{0} ; \mathrm{Z}=B \sqrt{c \alpha} / \lambda^{0} ; B-$ стала в емпіричному рівнянні Кольрауша $\lambda=\lambda^{0}-$ $B \sqrt{c} ; f_{ \pm}-$коефіцієнт активності.

Таблиця 1. Граничні молярні електропровідності $\lambda^{0}\left(\mathrm{Cм} \cdot \mathrm{cm}^{2} /\right.$ моль), що визначено методом Крауса-Брея для тіамін гідрохлориду у $\mathrm{H}_{2} \mathrm{O} / \mathrm{EtOH}$ та піридиній дихромату у $\mathrm{H}_{2} \mathrm{O} / \mathrm{DMFA}$ в інтервалі $283 \div 313 \mathrm{~K}$

\begin{tabular}{|c|c|c|c|c|c|c|}
\hline \multicolumn{7}{|c|}{ Тіамін гідрохлорид } \\
\hline \multirow{2}{*}{ Т, K } & 0 & 5 & 10 & 20 & 40 & 60 \\
\cline { 2 - 7 } & 163,61 & 126,15 & 109,68 & 86,05 & 56,16 & 46,54 \\
\hline 283 & 199,82 & 167,06 & 143,07 & 110,52 & 78,44 & 64,09 \\
\hline 293 & 239,00 & 206,18 & 180,23 & 148,64 & 103,67 & 82,18 \\
\hline 303 & 280,44 & 241,09 & 214,75 & 179,26 & 135,32 & 103,44 \\
\hline 313 & \multicolumn{7}{|c|}{ Піридиній дихромат } \\
\hline \multicolumn{7}{|c|}{$w$ (DMFA), \% } \\
\hline \multirow{2}{*}{ Т, K } & 0 & 40 & 60 & 80 & 100 \\
\hline 283 & 205,55 & 114,43 & 82,69 & 65,50 & 45,46 & 69,40 \\
\hline 293 & 221,58 & 160,03 & 111,73 & 72,09 & 61,21 & 80,87 \\
\hline 303 & 253,42 & 186,67 & 136,59 & 84,73 & 74,47 & 80,92 \\
\hline 313 & 303,49 & 257,58 & 175,13 & 101,99 & 89,66 & 99,40 \\
\hline
\end{tabular}


Фуосс склав таблицю зі значеннями $F(Z)$ для $Z=0 \div 0,209$ з кроком 0,001 [11], яка значно полегшила розрахунки констант за даними електропровідності. Розв'язок рівняння (6) включає ряд послідовних наближень. Спочатку будують графічну залежність $1 / \lambda$ від $c \lambda$ i таким чином знаходять величину $\lambda^{0}$. За значенням $\lambda^{0}$ визначають величину $Z$, приймаючи, що $\alpha=\lambda / \lambda^{0}$, і за таблицею знаходять значення $F(Z)$. Значення $B$ знаходять за рівнянням Онзагера [12]. За величиною $F(Z)$ розраховують приблизне значення $\alpha, 3$ якого отримують коефіцієнт активності $f_{ \pm}$. Потім будують графік у координатах $[F(Z) / \lambda]$ $\left[\lambda f_{ \pm}^{2} c / F(Z)\right]$ (рис. 2). За цим графіком знаходять значення $\lambda^{0} \mathrm{i}$, якщо воно співпадає 3 наближеним, розрахунок припиняють. $\mathrm{B}$ iншому разі розрахунок повторюють, приймаючи знайдене значення $\lambda^{0}$ за вихідне.

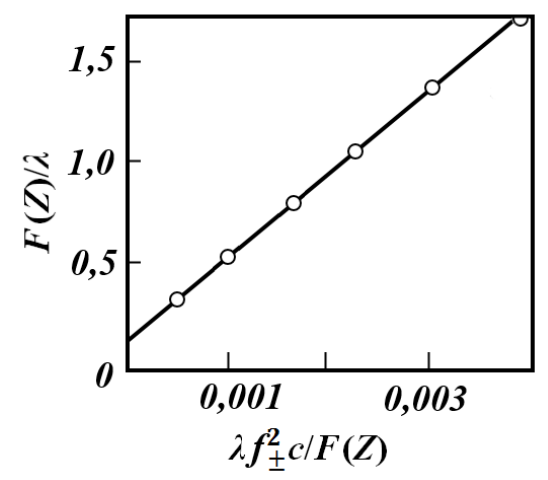

Рис. 2. Визначення $K_{c}$ і $\lambda^{0}$ для натрію гваяколату в розчинах гваяколу за температури $25{ }^{\circ} \mathrm{C}$ за методом Фyocca i Kpayca [5]

Послідовні наближення продовжують до тих пір, поки не отримають на графіку пряму лінію. Тоді відрізок, що пряма відтинає на осі ординат, відповідає величині $1 / \lambda^{0}$, а кутовий коефіцієнт - значенню $1 / K_{c}\left(\lambda^{0}\right)^{2}$, за яким і визначають термодинамічну константу $K_{c}$. Константу асоціації розраховують як величину, зворотну до $K_{c}: K_{a}=1 / K_{c}$.

Рівняння Фуосса-Крауса добре описує системи, де процеси асоціації переважають над дисоціацією, зокрема, розчини електролітів $з$ великими іонами. Тому його часто вико- ристовують для розрахунків констант асоціації ЧАС у чистих $\mathrm{i}$ змішаних розчинниках (табл. 2 і 3).

Таблиця 2. Молярні електропровідності і константи асоціації ЧАС у N,N-диметилацетаміді (DMAA) [4] i 1,3-діоксолані (DO) [2] за температури $25^{\circ} \mathrm{C}$

\begin{tabular}{|c|c|c|}
\hline ЧAC & $\lambda^{0}, \mathrm{CM}^{\cdot} \mathrm{cm}^{2} /$ моль & $K_{a}$, л/моль \\
\hline \multicolumn{3}{|c|}{ DMAA } \\
\hline $\mathrm{Et}_{4} \mathrm{NBr}^{a}{ }^{a}$ & 76,98 & 47,78 \\
\hline $\mathrm{Pr}_{4} \mathrm{NBr}$ & 72,03 & 58,31 \\
\hline $\mathrm{Bu}_{4} \mathrm{NBr}$ & 69,27 & 45,63 \\
\hline $\mathrm{Pen}_{4} \mathrm{NBr}$ & 62,30 & 51,03 \\
\hline $\mathrm{Hex}_{4} \mathrm{NBr}$ & 61,69 & 53,64 \\
\hline $\mathrm{Hep}_{4} \mathrm{NBr}$ & 61,35 & 58,15 \\
\hline $\mathrm{Oct}_{4} \mathrm{NBr}$ & 61,32 & 51,60 \\
\hline \multicolumn{3}{|c|}{ DO } \\
\hline $\mathrm{Me}_{4} \mathrm{NI}$ & 12,52 & $2,08 \cdot 10^{9}$ \\
\hline $\mathrm{Et}_{4} \mathrm{NBr}$ & 11,13 & $1,75 \cdot 10^{9}$ \\
\hline $\mathrm{Et}_{4} \mathrm{NI}$ & 11,65 & $0,99 \cdot 10^{9}$ \\
\hline $\mathrm{Pr}_{4} \mathrm{NBr}$ & 9,74 & $1,70 \cdot 10^{9}$ \\
\hline $\mathrm{Bu}_{4} \mathrm{NBr}$ & 9,04 & $1,02 \cdot 10^{9}$ \\
\hline $\mathrm{Bu}_{4} \mathrm{NI}$ & 9,57 & $1,01 \cdot 10^{9}$ \\
\hline $\mathrm{Hep}_{4} \mathrm{NBr}$ & 8,17 & $0,93 \cdot 10^{9}$ \\
\hline
\end{tabular}

a) Тут і далі в тексті позначення алкільних радикалів: $\mathrm{Me}$ - метил, $\mathrm{Et}-$ етил, $\mathrm{Pr}-\boldsymbol{H}$-пропіл, $\mathrm{Bu}-\boldsymbol{H}$-бутил, $\mathrm{Pen}-$

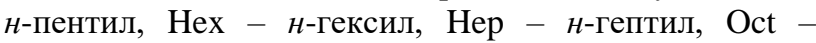
н-октил.

Оскільки в одному розчиннику величина граничної електропровідності змінюється, можна зробити висновок про ії̈ залежність від розміру іонів. Серед бромідів тетраалкіламонію найбільшу граничну електропровідність у DMAA має сіль 3 найменш об'ємним катіоном $-\mathrm{Et}_{4} \mathrm{NBr}$. ЧАС, що утворено однаковими катіонами, показують у DO більшу $\lambda^{0} 3$ аніоном I у порівнянні з $\mathrm{Br}^{-}$. Це свідчить про відносно велику рухливість цих іонів, тобто, за розміром малі катіони та великі аніони слабше сольватуються. Таким чином, характер взаємодії іонів електроліту з розчинником залежить від їхнього розміру і розподілу заряду.

Дослідження впливу температури на процеси асоціації показує (рис. 3), що зі збільшенням температури електропровідність розчинів відчутно зростає, отже, кількість вільних іонів - носіїв електричного заряду - при цьому також зростає, а частка асоціатів - зменшується. 
Вісник Донецького національного університету імені Василя Стуса. Сер. хімічні науки. № 1, 2017

Таблиця 3. Молярні електропровідності і константи асоціації ЧАС у ізопропанолі та його сумішах 3 водою [13] і $H$-гексанолі та його сумішах $з$ o-толуїдином [14] за температури $25^{\circ} \mathrm{C}$

\begin{tabular}{|c|c|c|c|}
\hline ЧАC & Розчинник & $\lambda^{0}, \mathrm{CM} \cdot \mathrm{cm}^{2} /$ моль & $K_{a}{ }^{a)}$, л/моль \\
\hline \multirow{8}{*}{$\mathrm{Bu}_{4} \mathrm{NClO}_{4}$} & вода/ізопропанол (10 \%) & 71,6 & 89 \\
\hline & вода/ізопропанол (30 \%) & 39,0 & 91 \\
\hline & вода/ізопропанол (50 \%) & 31,3 & 95 \\
\hline & вода/ізопропанол $(70$ \%) & 30,1 & 120 \\
\hline & вода/ізопропанол $(80$ \%) & 30,9 & 186 \\
\hline & вода/ізопропанол $(90$ \%) & 30,6 & 525 \\
\hline & вода/ізопропанол (95 \%) & 30,5 & 1047 \\
\hline & ізопропанол & 27,5 & 1862 \\
\hline \multirow{2}{*}{$\mathrm{Bu}_{4} \mathrm{NCl}$} & вода/ізопропанол $(90$ \%) & 26,6 & 148 \\
\hline & ізопропанол & 22,0 & 537 \\
\hline \multirow{9}{*}{$\mathrm{Bu}_{4} \mathrm{NPic}^{6)}$} & вода/ізопропанол (30 \%) & 23,8 & 145 \\
\hline & вода/ізопропанол (40 \%) & 21,1 & 145 \\
\hline & вода/ізопропанол (50 \%) & 20,2 & 117 \\
\hline & вода/ізопропанол $(60$ \%) & 20,2 & 120 \\
\hline & вода/ізопропанол (70 \%) & 22,7 & 100 \\
\hline & вода/ізопропанол (80 \%) & 22,9 & 141 \\
\hline & вода/ізопропанол $(90$ \%) & 24,6 & 214 \\
\hline & вода/ізопропанол (95 \%) & 24,1 & 372 \\
\hline & ізопропанол & 23,6 & 631 \\
\hline \multirow{8}{*}{$\mathrm{Bu}_{4} \mathrm{NOOCPh}$} & вода/ізопропанол (10 \%) & 44,7 & 81 \\
\hline & вода/ізопропанол (30 \%) & 25,0 & 93 \\
\hline & вода/ізопропанол (50 \%) & 21,0 & 100 \\
\hline & вода/ізопропанол $(70$ \%) & 18,0 & 107 \\
\hline & вода/ізопропанол $(80$ \%) & 20,4 & 110 \\
\hline & вода/ізопропанол (90 \%) & 19,8 & 148 \\
\hline & вода/ізопропанол $(95 \%)$ & 21,1 & 229 \\
\hline & ізопропанол & 21,0 & 513 \\
\hline \multirow{2}{*}{$\mathrm{Bu}_{4} \mathrm{NI}$} & $H$-гексанол & 1,09 & $7,10 \cdot 10^{3}$ \\
\hline & н-гексанол/o-толуїдин (25 \%) & 1,15 & $6,59 \cdot 10^{3}$ \\
\hline \multirow{2}{*}{$\mathrm{Pen}_{4} \mathrm{NI}$} & н-гексанол & 1,01 & $7,96 \cdot 10^{3}$ \\
\hline & н-гексанол/o-толуїдин (25 \%) & 1,02 & $7,09 \cdot 10^{3}$ \\
\hline \multirow{2}{*}{$\mathrm{Hex}_{4} \mathrm{NI}$} & $t$-гексанол & 0,90 & $8,82 \cdot 10^{3}$ \\
\hline & н-гексанол/o-толуїдин (25 \%) & 1,01 & $7,49 \cdot 10^{3}$ \\
\hline \multirow{2}{*}{$\mathrm{Hep}_{4} \mathrm{NI}$} & $t$-гексанол & 0,89 & $9,00 \cdot 10^{3}$ \\
\hline & н-гексанол/o-толуїдин (25 \%) & 0,99 & $8,08 \cdot 10^{3}$ \\
\hline
\end{tabular}

a) Значення $K_{a}$ за джерелом [13] розраховані з літературних даних $\mathrm{p} K_{c}$.

б) Тут і далі в тексті Ріс - пікрат (2,4,6-тринітрофенолят).
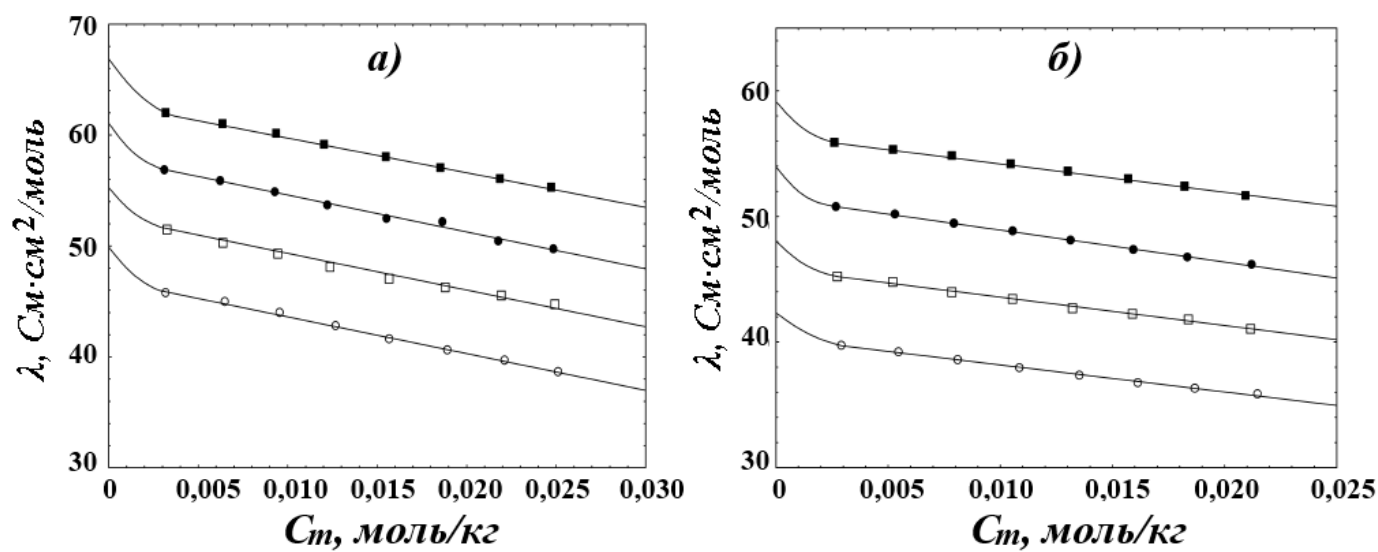

Рис. 3. Молярна електропровідність як функція моляльності для а) $\mathrm{Et}_{4} \mathrm{NBr}$; б) $\operatorname{Pr}_{4} \mathrm{NBr}$ у суміші води 3 2-бутоксіетанолом (40 \% мас.) [15]. Позначення: о 298,15 K; $\square 303,15 \mathrm{~K}$; • 308,15 K; • 313,15 K 


\section{3. Рівняння Лі-Уітона i його модифікації}

Модель, що запропоновано Фуоссом і Краусом, вже надає достатньо точне уявлення про міжіонні взаємодії у розчинах електролітів, однак вона розглядає розчинник як безструктурний континуум. Це спонукало У. Лі та Р. Уітона до розробки власної моделі [16], що описується складним поліноміальним рівнянням, яке наведено у редакції Петибриджа i Таба до вигляду (7) $[17,18]$ :

$\lambda=\gamma \lambda^{0}\left[1+C_{1}(\beta \kappa)+C_{2}(\beta \kappa)^{2}+C_{3}(\beta \kappa)^{3}\right]$

$\frac{\rho \kappa}{(1+\kappa R)}\left[1+C_{4}(\beta \kappa)+C_{5}(\beta \kappa)^{2}+\kappa R / 12\right]$

де $\gamma$ - частка неасоційованих (вільних) іонів; $C_{1}-C_{5}-$ складні функції від $\kappa R ; R-$ відстань між іонами в іонній парі, $\AA$; $\kappa$ - величина, що зворотна до радіусу іонної атмосфери; $\beta=$ $z^{2} e^{2} / D k T ; \rho=|z| F e /(299,79 \cdot 3 \pi \eta) ; D$ - діелектрична стала; $k$ - стала Больцмана; $F$ - стала Фарадея; $\eta$-в'язкість, пуаз; $e$ - заряд електрону; $z$ - заряд іону.

Рівняння (7) є справедливим для іонних пар симетричних електролітів. 3 метою подальшого полегшення розрахунку Петибридж і Таба також розклали функції $C_{1}-C_{5}$ у степеневі ряди (8)-(12) за параметром $t=\kappa R$ і $\ln t з$ точністю $0,01 \%$ у діапазоні $0,005<t<0,7$ :

$$
\begin{gathered}
C_{1}=-0,09753+0,08185 t-0,04144 t^{2} \\
+0,01114 t^{3} ; \\
C_{2}=0,11798-0,18737 t+0,09052 t^{2}- \\
0,02393 t^{3}+0,08358 \ln t \\
C_{3}=-0,19454+0,39764 t-0,37557 t^{2} \\
+0,25118 t^{3}-0,07843 t^{4}-0,10296 \ln t \\
C_{4}=-0,04724+0,06445 t-0,07419 t^{2} \\
+0,01784 t^{3}+0,12428 \ln t+ \\
0,09863 t \ln t ; \\
C_{5}=0,84185-0,90051 t+0,07809 t^{2}- \\
0,05333 t^{3}+0,50097 \ln t+ \\
0,45252 t \ln t
\end{gathered}
$$

Біанкі та Фернандез-Примі [19] розроблено і перевірено на валідність наближені залежності на основі рівняння Лі-Уітона. Вони отримали узагальнене рівняння (13), яке виконується для несиметричних електролітів та змішаних розчинників:

$$
\begin{aligned}
& \lambda=\lambda^{0}-S I^{1 / 2}+E I \ln I+J_{1} I- \\
& J_{2} I^{3 / 2}+E^{3 / 2} I^{3 / 2} \ln I+J_{3} I^{2},
\end{aligned}
$$

де $I$ - іонна сила розчину, моль/л; $S, E, J_{1}, J_{2}$, $E^{3 / 2}, J_{3}$ - коефіцієнти рівняння, що відповідають складеним виразам, що виведені авторами у відповідності з теорією Квінта-Вілларда.

На рис. 4 наведено залежності електропровідності водних розчинів $\mathrm{NaCl}$ та $\mathrm{MgCl}_{2}$ від іонної сили згідно рівняння (13) та його наближеними формами. Криві LW1 репрезентують повну форму рівняння (13), LW2 - цей же вираз з $J_{3}=0$, LW3 $-3 J_{2}, E^{3 / 2}, J_{3}=0$.

Виходячи з отриманих графіків, автори дослідження зробили висновок, що рівняння (13) (крива LW1) цілком задовільно описує розведені розчини слабких електролітів. При цьому рівняння у формі LW2 може бути застосовано лише для дуже розведених розчинів, а найпростіша форма LW3 є неприйнятною, оскільки навіть якісно не відповідає поведінці електролітів у розчинах будь-якої концентрації.

Спроби спростити повне рівняння Лі-Уітона спричинені його значною складністю та великим обсягом розрахунків для його розв'язку, що впливає на час, необхідний для обчислень, та ймовірність допущення помилок. Сучасне комп'ютерне обладнання та програмне забезпечення суттєво спрощують задачу пошуку коефіцієнтів у рівнянні Лі-Уітона і подальшого знаходження величин $K_{a}$. Так, комп'ютерну обробку експериментальних даних концентрації електроліту і його молярної електропровідності можливо провести засобами програми Microsoft Excel та iii надбудови Fitter [20]. Алгоритм розрахунку програмується в макросі, і при його виконанні значення граничної молярної електропровідності $\lambda^{0}$, міжіонної відстані $R$ і константи асоціації $K_{a}$ разом з їх довірчим інтервалом знаходяться автоматично, що суттєво скорочує час обчислень. 
Вісник Донецького національного університету імені Василя Стуса. Сер. хімічні науки. № 1, 2017

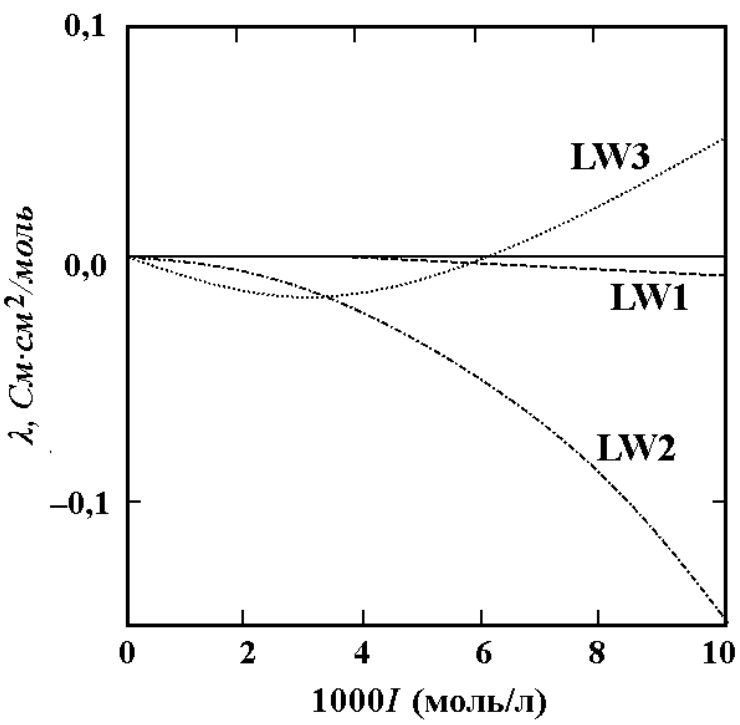

a)

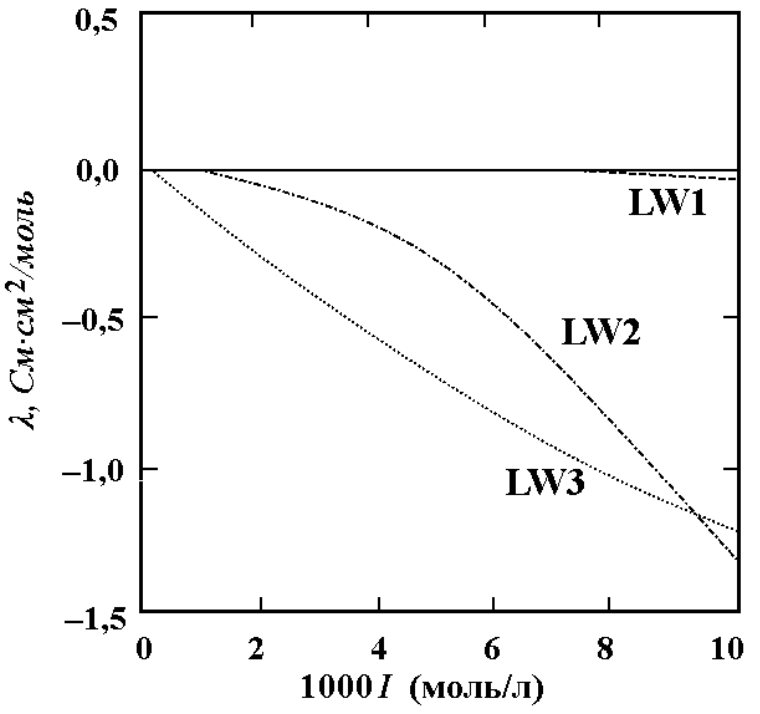

б)

Рис. 4. Залежність електропровідності водних розчинів: а) $\mathrm{NaCl}$; б) $\mathrm{MgCl}_{2}$ від іонної сили із застосуванням різних наближених рівнянь Лі-Уітона. Тип наближення вказано на графіках

Завдяки можливості достатньо простого та швидкого розрахунку, задовільній точності i застосовності до відносно великого діапазону концентрацій симетричних, несиметричних та змішаних електролітів рівняння Лі-Уітона на сьогоднішній день $є$ найбільш універсальною математичною моделлю іон-іонних та іон-дипольних взаємодій у розчинах. Для серій перхлоратів та пікратів тетраалкіламонію у чистих і змішаних розчинниках цим методом визначено параметри $\lambda^{0}, R \mathrm{i} \log K_{a}$ (табл. 4).

Збільшення частки асоціатів у розчині зі зниженням полярності розчинника підтверджено дослідженням [23], в якому діелектричну проникність середовища варіювали шляхом зміни співвідношення компонентів змішаного розчинника. Виявилося, що між $\log K_{a}$ та величиною, зворотною до значення діелектричної сталої $\varepsilon_{r}$, існує лінійна залежність (рис. 5). Зменшення діелектричної сталої, тобто полярності розчинника, приводить до збільшення $\log K_{a}$, відповідно, частки іонних асоціатів у системі. Подібні залежності, що отримано іншими методами, було розглянуто вище.
Таблиця 4. Гранична молярна провідність $\lambda^{0}$, міжіонна відстань $R$ і логарифм константи асоціації

$\log K_{a}$, що визначено за рівнянням Лі-Уітона

\begin{tabular}{|c|c|c|c|}
\hline ЧAC & $\lambda^{0}, \mathrm{CM}^{\cdot} \mathrm{cm}^{2} /$ моль & $R, \mathrm{HM}$ & $\log K_{a}$ \\
\hline \multicolumn{4}{|c|}{ Ацетон [21] } \\
\hline $\mathrm{Me}_{3} \mathrm{CetNClO}{ }_{4}{ }^{a)}$ & 185 & 0,767 & 2,34 \\
\hline $\mathrm{Pen}_{4} \mathrm{NClO}_{4}$ & 187 & 0,792 & 2,17 \\
\hline$\pi_{-}^{\oplus}-$ Cet $\stackrel{\ominus}{\mathrm{ClO}_{4}}$ & 185 & 0,774 & 2,30 \\
\hline \multicolumn{4}{|c|}{ Метилізобутилкетон [22] } \\
\hline $\mathrm{Me}_{4} \mathrm{NClO}_{4}$ & 122,8 & 0,72 & 3,87 \\
\hline $\mathrm{Et}_{4} \mathrm{NClO}_{4}$ & 107,4 & 0,78 & 3,75 \\
\hline $\mathrm{Pr}_{4} \mathrm{NClO}_{4}$ & 102,2 & 0,85 & 3,52 \\
\hline $\mathrm{Bu}_{4} \mathrm{NClO}_{4}$ & 96,1 & 0,89 & 3,45 \\
\hline $\mathrm{Pen}_{4} \mathrm{NClO}_{4}$ & 92,0 & 0,93 & 3,43 \\
\hline $\mathrm{Hex}_{4} \mathrm{NClO}_{4}$ & 89,6 & 0,97 & 3,38 \\
\hline $\mathrm{Hep}_{4} \mathrm{NClO}_{4}$ & 90,3 & 1,00 & 3,40 \\
\hline $\mathrm{Et}_{3} \mathrm{HexNClO}_{4}$ & 101,9 & 0,85 & 3,50 \\
\hline $\mathrm{Me}_{3} \mathrm{CetNClO}_{4}$ & 92,0 & 0,91 & 3,76 \\
\hline $\mathrm{Me}_{3} \mathrm{StrNClO}_{4}$ & 90,0 & 0,93 & 3,75 \\
\hline${ }_{=}^{\oplus}-\mathrm{Bu} \stackrel{\ominus}{\mathrm{ClO}_{4}}$ & 102,7 & 0,78 & 3,69 \\
\hline$\pi_{-}^{\mathrm{N}}-\mathrm{Cet} \stackrel{\ominus}{\mathrm{ClO}_{4}}$ & 91,8 & 0,91 & 3,68 \\
\hline $\mathrm{Et}_{4} \mathrm{NPic}$ & 96,3 & 0,91 & 3,05 \\
\hline $\mathrm{Bu}_{4} \mathrm{NPic}$ & 85,0 & 1,01 & 3,03 \\
\hline \multicolumn{4}{|c|}{ Ацетон/н-гексан (1:1) [23] } \\
\hline $\mathrm{Et}_{4} \mathrm{NPic}$ & 193 & 1,1 & 4,20 \\
\hline $\mathrm{Me}_{3}$ CetNPic & 123 & 1,2 & 4,35 \\
\hline${ }_{=}^{\oplus} \stackrel{\oplus}{N}-$ Cet $\stackrel{\ominus}{\text { Pic }}$ & 134 & 1,2 & 4,38 \\
\hline
\end{tabular}

a) Тут $\mathrm{Cet}$ - цетил $\left(\mathrm{C}_{16} \mathrm{H}_{33}\right) ; \mathrm{Str}$ - стеарил $\left(\mathrm{C}_{18} \mathrm{H}_{35}\right)$. 


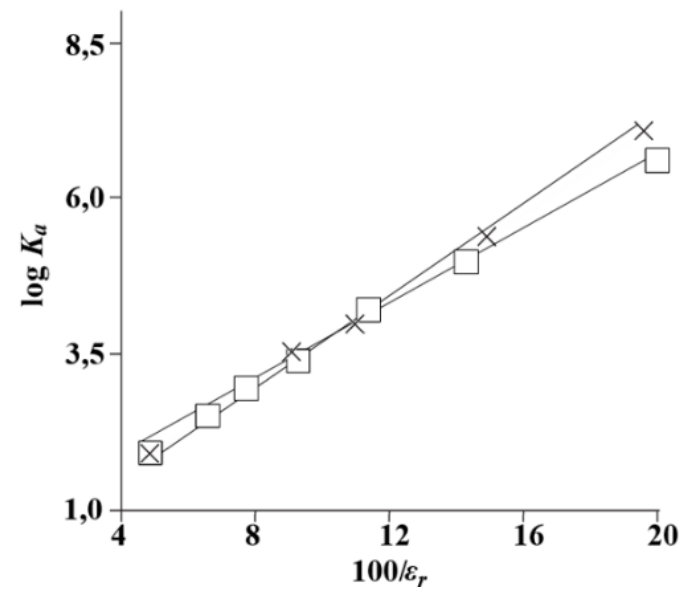

Рис. 5. Залежність $\log K_{a}$ від $100 / \varepsilon_{r}$ для розчинів тетрабутиламоній пікрату у ацетон- - -бутилацетатних $(\times)$ та ацетон- $н$-гексанових ( $\square)$ змішаних розчинниках за температури $25{ }^{\circ} \mathrm{C}$

Отже, усі наведені математичні моделі достовірно передають якісний характер іонних рівноваг у системах. Вибір методу обробки експериментальних даних залежить від конкретної системи та потрібного рівня точності.

\section{4. Інші моделі і методи}

Розвиток теорії електропровідності розчинів електролітів сьогодні продовжується. Як правило, нові системи рівнянь є комбінаціями та інтерпретаціями підходів, що розглянуто в даній роботі, наприклад, модель Бартела [24, 25] або Турка-Блума-Бернарда-Кунца [26]. Оскільки на сьогодні ще не створено ідеальної моделі іон-іонної та іон-дипольної взаємодії, яка б абсолютно достовірно відтворювала стан компонентів розчину через величини електропровідності, дослідники звертаються також до інших способів вивчення процесів асоціації електролітів. Так, значення $K_{a}$, що визначено методом спектрофотометрії, співпадають 3 результатами вимірювань іншими фізичними методами у межах 0,01-0,04 одиниць [27]. Перспективним напрямом прогнозування поведінки іонів $є$ квантово-хімічні методи, які дають змогу розрахувати електростатичні та термодинамічні параметри усіх можливих станів системи $[28,29]$.

\section{Висновки}

Четвертинні амонієві солі є зручними об'єктами дослідження процесів іонної асоціації, оскільки для них є характерним утворення іонних пар і трійників. Рівняння, що ро- зглянуті у даній роботі, дають приблизно однакові значення $\lambda^{0}$, але величини констант дисоціації узгоджуються між собою лише в межах одного порядку. Моделі, що обрано для побудови того чи іншого математичного апарату для визначення констант дисоціації, $\epsilon$ умовними і не відповідають справжнім умовам повною мірою, тому не слід очікувати, що параметри міжіонної відстані будуть мати реальній фізичний зміст. Тому порівняння результатів розрахунків за кондуктометричними даними має сенс тільки в тому випадку, коли вони отримані за одним і тим же рівнянням. Якісні ж закономірності однаковою мірою простежуються в рамках існуючих моделей і відповідають сучасним уявленням про складний характер рівноваг у розчинах електролітів.

\section{Список літератури}

1. Ion pairs, nucleophilicity and salt effects in bimolecular nucleophilic substitution / Winstein S., Savedoff L. G., Smith S. et al. Tetrahedron Letters. 1960. Vol. 1, N 30. P. 24-30. DOI: 10.1016/S00404039(01)99296-2.

2. Sinha A., Roy M. N. Ion-pair and triple-ion studies of some tetraalkylammonium halides in pure 1,3-dioxolane at 298.5 K. Journal of Molecular Liquids. 2008. Vol. 140. P. 39-44. DOI: 10.1016/j.molliq.2008.01.001.

3. Харнед Г., Оуэн Б. Физическая химия растворов электролитов. Москва: Издательство иностранной литературы, $1952.628 \mathrm{c}$.

4. Das D., Das B., Hazra D. K. Electrical Conductance of Some Symmetrical Tetraalkylammonium and Alkali Salts in N, N-Dimethylacetamide at $25^{\circ} \mathrm{C}$. Journal of Solution Chemistry. 2003. Vol. 3, N 1. P. 77-83. DOI: 10.1023/A:1022648916138.

5. Измайлов Н. А. Электрохимия растворов. Москва: Химия, 1976. 488 с.

6. Евстратова К. И., Купина Н. А., Малахова Е. Е. Физическая и коллоидная химия. Москва: Высшая школа, 1990. $487 \mathrm{c}$.

7. Kraus C. A., Bray W. C. A general relation between the concentration and the conductance of ionized substances in various solvents. J. Amer. Chem. Soc. 1913. Vol. 35, N 10. P. 1315-1434. DOI: 10.1021/ja02199a001.

8. Bhat J. I., Shetty M. K. Studies on the Effect of Ethanol on the Solvation Behaviour of Thiamine Hydrochloride in Water. Russian Journal of Electrochemistry. 2012. Vol. 48, N 5. P. 495-501. DOI: 10.1134/S1023193512050047.

9. Radhika V., Manikyamba P. Ion-Solvation Behavior of Pyridinium Dichromate in Water- $\mathrm{N}, \mathrm{N}$ Dimethyl Formamide Solvent Mixtures. 2012. Journal of Solution Chemistry. Vol. 41, N 2. P. 261-270. DOI: 10.1007/s10953-012-9804-9. 
10. Fuoss R. M., Kraus C. A. Properties of Electrolytic Solutions. II. The Evaluations of $\lambda^{0}$ and of $\mathrm{K}$ for Incompletely Dissociated Electrolytes. J. Amer. Chem. Soc. 1933. Vol. 55, N 2. P. 476-488. DOI: $10.1021 / \mathrm{ja01329a006.}$

11. Fuoss R. M. Solution of the Conductance Equation. J. Amer. Chem. Soc. 1935. Vol. 57, N 3. P. 488489. DOI: $10.1021 / \mathrm{ja0} 1306 \mathrm{a} 502$.

12. Сафонова Л. П.,

Колкер А. М. Кондуктометрия растворов электролитов. Успехи химии. 1992. Том 61, №9. С. 1748-1775. DOI: 10.1070/RC1992v061n09ABEH001009.

13. Roses M., Bonet M. J., Bosch E. Conductometric determination of dissociation constants of several acids and their tetrabutylammonium salts in propan-2-ol/water mixtures. Analytica Chimica Acta. 1996. Vol. 333, N 3. P. 241-247. doi:10.1016/0003-2670(96)00286-3.

14. Roy M. N., Sarkar L., Dewan R. Ion-pair and triple-ion formation of some tetraalkylammonium iodides in n-hexanol and its binary mixtures with o-toluidine. $J$. Chem. Thermodynamics. 2011. Vol. 43, N 3. P. 371-376. DOI: $10.1016 /$ j.jct.2010.10.008.

15. Das C. Electrical Conductance of Some Tetraalkylammonium Bromide Salts in 2-Butoxyethanol (1) + Water (2) mixtures at $(298.15,303.15,308.15$, and 313.15) K . J. Chem. Eng. Data. 2014. Vol. 59, N 2. P. 168175. DOI: $10.1021 /$ je4004405.

16. Lee W. H., Wheaton R. J. Conductance of Symmetrical, Unsymmetrical and Mixed Electrolytes. Part 3. Examination of New Model and Analysis of Data for Symmetrical Electrolytes. J.C.S. Faraday II. 1979. N 75. P. 1128-1145. DOI: 10.1039/f29797501128.

17. Pethybridge A. D., Taba S. S. Precise Conductimetric Studies on Aqueous Solutions of 2:2 Electrolytes. Part 2.Analysis of Data for $\mathrm{MgSO}_{4}$ in Terms of New Equations from Fuoss and from Lee and Wheaton. J.C.S. Faraday I. 1980. N 76. P. 368-376. DOI: 10.1039/f19807600368.

18. Tyunina E. Y., Afanasiev V. N., Chekunova M. D. Electroconductivity of Tetraethylammonium Tetrafluoroborate in Propylene Carbonate at Various Temperatures. J. Chem. Eng. Data. 2011. Vol. 56, N 7. P. 3222-3226. DOI: 10.1021/je200309v.

19. Bianchi H., Fernandez-Prini R. The Conductivity of Dilute Electrolyte Solutions: Expanded Lee and Wheaton Equation for Symmetrical, Unsymmetrical and Mixed Electrolytes. Journal of Solution Chemistry. 1993. Vol. 22, N 6. P. 557-570. DOI: 10.1007/BF00646931.

20. Чумак В. Л., Максимюк М. Р., Нешта Т. В., Босак Ю. С. Визначення коефіцієнтів рівняння Лі Уітона для електропровідності розчинів електролітів в середовищі MS Excel. Восточно-Европейский журнал передовых технологий. 2013. Т. 2, № 5 (62). С. 59-63.
21. Гога С. Т. Проводимость и константы ионной ассоциации перхлоратов цетилтриметиламмония, тетра-н-пентиламмония и $\mathrm{N}$-цетилпиридиния в ацетоне при 298.15 K. Вісник Харківського національного університету. Серія Хімія. 2010. Т. 932, №19 (42). C. 93-95.

22. Goga S. T., Lebed A. V., Mchedlov-Petrossyan N. O. Conductivity and Dissociation Constants of Quaternary Ammonium Perchlorates and Picrates in 4-Methyl-pentan-2-one. J. Chem. Eng. Data. 2010. Vol. 55, N 5. P. 1887-1892. DOI: 10.1021/je9008969.

23. Palval I. N., Lebed A. V., Mchedlov-Petrossyan N. O. Association and transport properties in solvents of medium and low relative permittivity: Quaternary ammonium picrates in acetone-n-hexane mixed solvents. Journal of Molecular Liquids. 2011. Vol. 158, N 1. P. 33-37. DOI: 10.1016/j.molliq.2010.10.004.

24. Bešter-Rogač M., Klofutar C., Rudan-Tasic D. Association of hydrophobic ions in aqueous solution: A conductometric study of symmetrical tetraalkylammonium cyclohexylsulfamates. Journal of Molecular Liquids. 2010. Vol. 156, N 1. P. 82-88. DOI: 10.1016/j.molliq. 2010.03.016

25. Salamanca Y. P., Blanco L. H., Buchner R., Vargas E. F. Electrical Conductivity Studies of Tetraalkylammonium Bromides in Aqueous Solutions at Several Temperatures. J. Chem. Eng. Data. 2012. Vol. 57, N 8. P. 2203-2210. DOI: 10.1021/je101043c.

26. Arcis H., Ferguson J. P., Zimmermanb G. H., Tremaine P. R. The limiting conductivity of the borate ion and its ion-pair formation constants with sodium and potassium under hydrothermal conditions. Phys. Chem. Chem. Phys. 2016. Vol. 18, N 34. P. 24081-24094. DOI: 10.1039/C6CP03084J.

27. Пальваль И. Н., Лебедь А. В., МчедловПетросян Н. О. Ассоциация ионов пикрата и калия в апротонном растворителе: исследование методами кондуктометрии и спектрофотометрии. Вісник Харківського національного університету. Серія Хімія. 2010. Том 895, № 18 (41). С. 189-197.

28. Shields G. C., Seybold P. G. Computational Approaches for the Prediction of pKa Values. USA, Boca Raton: CRC Press, 2014. 175 p.

29. Fry A. J. Computational Studies of Ion Pairing. 7. Ion-Pairing and Association Effects between Tetraalkylammonium Ions and Nitrobenzene Redox Species. "Ion Pairing" to Neutral Substances. J. Org. Chem. 2013. Vol. 78, N 5. P. 2111-2117. DOI: 10.1021/ jo302385r.

Рукопис надійшов до редакиії 25.11.2016 
УДК 543.555+544.353.3+543.632.562.4

Эволюция кондуктометрического подхода к установлению поведения ионов четвертичных аммониевых солей в растворах

К. С. Ютилова, Е. Н. Швед

Рассмотрен метод кондуктометрии как способ определения констант ионного равновесия в растворах электролитов. Описаны модели ионной ассоциации и методы математической обработки кондуктометрических данных - от классических до современных. Адекватность моделей проиллюстрирована экспериментальными примерами. Проанализированы зависимости молярной предельной электропроводности от свойств электролита и растворителя. Показано, что в растворах четвертичных аммониевых солей происходят процессы ассоциации.

Ключевые слова: электропроводность, кондуктометрия, четвертичные аммониевые соли, ионные пары, константа ассоциации.

Evolution of conductometry approach to quaternary ammonium salts behavior determination in solutions

K. S. Yutilova, O. M. Shved

Vasyl' Stus Donetsk National University, Vinnytsia, Ukraine

The conductometric method was examined as a way to determine ion equilibrium constants in electrolyte solutions. Problematical character of conductivity determination of salts in non-aqueous media was specified. Ion association models and conductivity data mathematical processing methods from classic to modern were characterized. Comparative analysis of particle state determination presented by using Kraus - Bray, Fuoss - Kraus, Lee - Wheaton equations. The adequacy of the models was illustrated by the experimental examples. Correlations between limiting molar conductivity and properties of electrolyte and solvent were analyzed. Quaternary ammonium salts tendency to association in organic solvents, in particular to ion pairs and triplets formation, was shown. Electrolyte solution conductivity theory development was concerned as promising scientific direction for creating a versatile and reliable ion interaction model in solution.

Keywords: conductivity, conductometry, quaternary ammonium salts, ion pairs, association constant.

References

1. Winstein, S.; Savedoff, L. G.; Smith, S.; Stevens, I. D. R.; Gall, J. S. Ion pairs, nucleophilicity and salt effects in bimolecular nucleophilic substitution. Tetrahedron Letters 1960, 1 (30), 24-30 DOI: 10.1016/s0040-4039(01)99296-2.

2. Sinha, A.; Roy, M. N. Ion-pair and triple-ion studies of some tetraalkylammonium halides in pure 1,3-dioxolane at 298.15 K. Journal of Molecular Liquids 2008, 140 (1-3), 39-44 DOI: 10.1016/j.molliq.2008.01.001.

3. Kharned, G.; Ouen, B. Fizicheskaia khimiia rastvorov elektrolitov [The physical chemistry of electrolyte solutions]. Moskva: Izdatelstvo inostrannoi literatury, 1952. (in Russian)

4. Das, D.; Das, B.; Hazra, D. K. Electrical Conductance of Some Symmetrical Tetraalkylammonium and Alkali Salts in N, N-Dimethylacetamide at $25{ }^{\circ} \mathrm{C}$. Journal of Solution Chemistry 2003, 3 (1), 77-83 DOI: 10.1023/A:1022648916138.

5. Izmailov, N. A. Elektrokhimiia rastvorov [The electrochemistry of solutions]. Moskva: Khimiia, 1976. (in Russian)

6. Evstratova K. I., Kupina N. A., Malakhova E. E. Fizicheskaia i kolloidnaia khimiia [Physical and colloid chemistry]. Moskva: Vysshaia shkola, 1990. (in Russian)

7. Kraus, C. A.; Bray, W. C. A General Relation Between The Concentration And The Conductance Of Ionized Substances In Various Solvents. Journal of the American Chemical Society 1913, 35 (10), 1315-1434 DOI: 10.1021/ja02199a001.

8. Bhat, J. I.; Shetty, M. K. Studies on the effect of ethanol on the solvation behaviour of thiamine hydrochloride in water. Russian Journal of Electrochemistry 2012, 48 (5), 495-501 DOI: 10.1134/s1023193512050047.

9. Radhika, V.; Manikyamba, P. Ion-Solvation Behavior of Pyridinium Dichromate in Water-N,N-Dimethyl Formamide Solvent Mixtures. Journal of Solution Chemistry 2012, 41 (2), 261-270 DOI: 10.1007/s10953-012-9804-9.

10. Fuoss, R. M.; Kraus, C. A. Properties of Electrolytic Solutions. II. The Evaluations of $\Lambda^{0}$ and of K for Incompletely Dissociated Electrolytes. Journal of the American Chemical Society 1933, 55 (2), 476-488 DOI: $10.1021 / \mathrm{ja01329a006.}$

11. Fuoss, R. M. Solution of the Conductance Equation. Journal of the American Chemical Society 1935,57 (3), 488-489 DOI: 10.1021/ja01306a502.

12. Safonova, L. P.; Kolker, A. M. Conductometry of electrolyte solutions. Uspekhi khimii 1992, 61 (9), 1748-1775 DOI: 10.1070/rc1992v061n09abeh001009.

13. Rosés, M.; Bonet, M.; Bosch, E. Conductometric determination of dissociation constants of several acids and their tetrabutylammonium salts in propan-2-ol/water mixtures. Analytica Chimica Acta 1996, 333 (3), $241-247$ DOI: 10.1016/0003-2670(96)00286-3.

14. Roy, M. N.; Sarkar, L.; Dewan, R. Ion-pair and triple-ion formation of some tetraalkylammonium iodides in nhexanol and its binary mixtures with o-toluidine. The Journal of Chemical Thermodynamics 2011, 43 (3), 371-376 DOI: 10.1016/j.jct.2010.10.008. 
15. Das, C. Electrical Conductance of Some Tetraalkylammonium Bromide Salts in 2-Butoxyethanol (1) Water (2) mixtures at $(298.15,303.15,308.15$, and 313.15) K. Journal of Chemical \& Engineering Data J. Chem. Eng. Data 2014, 59 (2), 168-175 DOI: $10.1021 / \mathrm{je} 4004405$.

16. Lee, W. H.; Wheaton, R. J. Conductance of symmetrical, unsymmetrical and mixed electrolytes. Part 3.Examination of new model and analysis of data for symmetrical electrolytes. J. Chem. Soc., Faraday Trans. 2 1979, 75, 1128-1145 DOI: 10.1039/f29797501128.

17. Pethybridge, A. D.; Taba, S. S. Precise conductimetric studies on aqueous solutions of 2:2 electrolytes. Part 2.Analysis of data for MgSO4 in terms of new equations from Fuoss and from Lee and Wheaton. Journal of the Chemical Society, Faraday Transactions 1: Physical Chemistry in Condensed Phases 1980, 76, 368-376 DOI: 10.1039/f19807600368.

18. Tyunina, E. Y.; Afanasiev, V. N.; Chekunova, M. D. Electroconductivity of Tetraethylammonium Tetrafluoroborate in Propylene Carbonate at Various Temperatures. Journal of Chemical \& Engineering Data J. Chem. Eng. Data 2011, 56 (7), 3222-3226 DOI: 10.1021/je200309v.

19. Bianchi, H.; Fernandez-Prini, R. The conductivity of dilute electrolyte solutions: Expanded lee and wheaton equation for symmetrical, unsymmetrical and mixed electrolytes. Journal of Solution Chemistry 1993, 22 (6), 557-570 DOI: $10.1007 / \mathrm{bf00646931.}$

20. Chumak, V. L.; Maksymiuk, M. R.; Neshta, T. V.; Bosak, Iu. S. Vyznachennia koefitsiientiv rivniannia Li Uitona dlia elektroprovidnosti rozchyniv elektrolitiv v seredovyshchi MS Excel [Determination of coefficients of Lee Wheaton equation for electrical conductivity of electrolyte solutions in MS Excel]. Vostochno-Evropeiskii zhurnal peredovykh tekhnologii 2013, 2 (5 (62)), 59-63. (in Ukrainian)

21. Goga, S. T. Provodimost i konstanty ionnoi assotciatcii perkhloratov tcetiltrimetilammoniia, tetra-npentilammoniia i N-tcetilpiridiniia $\mathrm{v}$ atcetone pri $298.15 \mathrm{~K}$ [Conductance and ion association constants of cetyltrimethylammonium, tetra-n-pentylammonium and N-cetylpyridinium perchlorates in acetone at 298.15 K].Visnyk Kharkivskoho natsionalnoho universytetu. Seriia Khimiia 2010, 932 (19 (42)), 93-95. (in Russian)

22. Goga, S. T.; Lebed, A. V.; Mchedlov-Petrossyan, N. O. Conductivity and Dissociation Constants of Quaternary Ammonium Perchlorates and Picrates in 4-Methyl-pentan-2-one. Journal of Chemical \& Engineering Data J. Chem. Eng. Data 2010, 55 (5), 1887-1892 DOI: 10.1021/je9008969.

23. Palval, I. N.; Lebed, A. V.; Mchedlov-Petrossyan, N. O. Association and transport properties in solvents of medium and low relative permittivity: Quaternary ammonium picrates in acetone-n-hexane mixed solvents. Journal of Molecular Liquids 2011, 158 (1), 33-37 DOI: 10.1016/j.molliq.2010.10.004.

24. Bešter-Rogač, M.; Klofutar, C.; Rudan-Tasic, D. Association of hydrophobic ions in aqueous solution: A conductometric study of symmetrical tetraalkylammonium cyclohexylsulfamates. Journal of Molecular Liquids 2010, 156 (1), 82-88 DOI: 10.1016/j.molliq.2010.03.016.

25. Salamanca, Y. P.; Blanco, L. H.; Buchner, R.; Vargas, E. F. Electrical Conductivity Studies of Tetraalkylammonium Bromides in Aqueous Solutions at Several Temperatures. Journal of Chemical \& Engineering Data J. Chem. Eng. Data 2012, 57 (8), 2203-2210 DOI: 10.1021/je101043c.

26. Arcis, H.; Ferguson, J. P.; Zimmerman, G. H.; Tremaine, P. R. The limiting conductivity of the borate ion and its ion-pair formation constants with sodium and potassium under hydrothermal conditions. Phys. Chem. Chem. Phys. 2016, 18 (34), 24081-24094 DOI: 10.1039/c6cp03084j.

27. Palval, I. N.; Lebed, A. V.; Mchedlov-Petrosian, N. O. Assotciatciia ionov pikrata i kaliia v aprotonnom rastvoritele: issledovanie metodami konduktometrii i spektrofotometrii [The association of picrate and potassium ions in aprotic solvent: a conductance and spectrophotometry study]. Visnyk Kharkivskoho natsionalnoho universytetu. Seriia Khimiia 2010, 895 (18 (41)), 189-197. (in Russian)

28. Shields, G. C.; Seybold, P. G. Computational approaches for the prediction of pKa values; CRC Press: Boca Raton, 2014.

29. Fry, A. J. Computational Studies of Ion Pairing. 7. Ion-Pairing and Association Effects between Tetraalkylammonium Ions and Nitrobenzene Redox Species. "Ion Pairing" to Neutral Substances. J. Org. Chem. 2013, 78 (5), 2111-2117 DOI: 10.1021/jo302385r. 